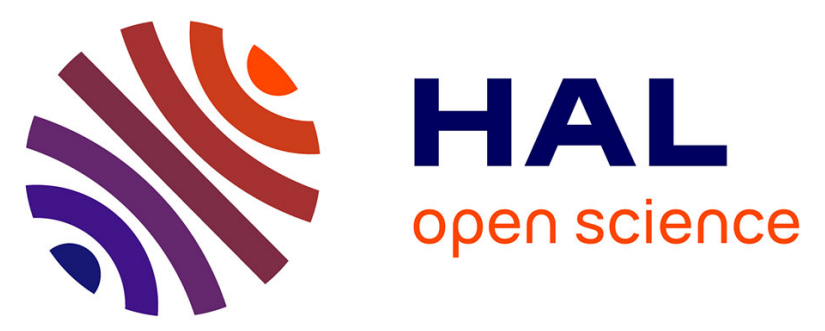

\title{
Brain Substrates of Time-Based Prospective Memory Decline in Aging: A Voxel-Based Morphometry and Diffusion Tensor Imaging Study
}

Alexandrine Morand, Shailendra Segobin, Grégory Lecouvey, Julie Gonneaud, Francis Eustache, Géraldine Géraldine Rauchs, Béatrice Desgranges

\section{To cite this version:}

Alexandrine Morand, Shailendra Segobin, Grégory Lecouvey, Julie Gonneaud, Francis Eustache, et al.. Brain Substrates of Time-Based Prospective Memory Decline in Aging: A Voxel-Based Morphometry and Diffusion Tensor Imaging Study: Neural substrates of prospective memory decline in aging. Cerebral Cortex, In press, 10.1093/cercor/bhaa232 . inserm-02933201

\section{HAL Id: inserm-02933201 https://www.hal.inserm.fr/inserm-02933201}

Submitted on 8 Sep 2020

HAL is a multi-disciplinary open access archive for the deposit and dissemination of scientific research documents, whether they are published or not. The documents may come from teaching and research institutions in France or abroad, or from public or private research centers.
L'archive ouverte pluridisciplinaire HAL, est destinée au dépôt et à la diffusion de documents scientifiques de niveau recherche, publiés ou non, émanant des établissements d'enseignement et de recherche français ou étrangers, des laboratoires publics ou privés. 


\section{Brain Substrates of Time-Based Prospective Memory Decline in Aging: A Voxel-Based Morphometry and Diffusion Tensor Imaging Study}

Alexandrine Morand ${ }^{\mathrm{a}}$, Shailendra Segobin ${ }^{\mathrm{a}}$, Grégory Lecouvey ${ }^{\mathrm{a}}$, Julie Gonneaud $^{\mathrm{a}}$, Francis Eustache $^{\mathrm{a}}$, Géraldine Rauchs ${ }^{\mathrm{a}}$ and Béatrice Desgranges ${ }^{\mathrm{a}^{*}}$

${ }^{a}$ Normandie Université, UNICAEN, PSL Université Paris, EPHE, Inserm, U1077, CHU de Caen, Neuropsychologie et Imagerie de la Mémoire Humaine, GIP Cyceron, 14000 Caen, France

*Correspondence:

Béatrice Desgranges

Neuropsychologie et Imagerie de la Mémoire Humaine (NIMH)

Pôle des Formations et de Recherche en Santé (PFRS)

2 , rue des Rochambelles

F-14032 Caen Cedex CS 14032

France

Tel.: +33(0)2 31568381

Fax: +33(0)231568391

beatrice.desgranges@unicaen.fr

Running title: Neural substrates of prospective memory decline in aging 


\begin{abstract}
Time-based prospective memory (TBPM) allows us to remember to perform intended actions at a specific time in the future. TBPM is sensitive to the effects of age, but the neural substrates of this decline are still poorly understood. The aim of the present study was thus to better characterize the brain substrates of the age-related decline in TBPM, focusing on macrostructural gray-matter and microstructural white-matter integrity. We administered a TBPM task to 22 healthy young $(26 \pm 5.2$ years) and 23 older $(63 \pm 5.9$ years $)$ participants, who also underwent volumetric magnetic resonance imaging and diffusion tensor imaging scans. Neuroimaging analyses revealed lower gray-matter volumes in several brain areas in older participants, but these did not correlate with TBPM performance. By contrast, an age-related decline in fractional anisotropy in several white-matter tracts connecting frontal and occipital regions did correlate with TBPM performance, while there was no significant correlation in healthy young subjects. According to the literature, these tracts are connected to the anterior prefrontal cortex and the thalamus, two structures involved in TBPM. These results confirm the view that a disconnection process occurs in aging and contributes to cognitive decline.
\end{abstract}

Keywords: Aging; Diffusion tensor imaging; Episodic memory; Prospective memory; Voxel-based morphometry 


\section{Introduction}

Prospective memory (PM) is defined as the ability to execute intended actions at an appropriate time in the future. PM is crucial in our life enabling us to remember to buy something at the supermarket after work or to take medication each day (Einstein and McDaniel 1990). Consequently, older people consulting for memory problems often complain of PM lapses. Two forms of PM are usually distinguished, according to the nature of the cue triggering retrieval. Retrieval of an intention can be triggered either by the occurrence of an external event (prospective cue; e.g., "take the roast out of the oven when the timer rings"), corresponding to event-based PM (EBPM), or after a predefined amount of time (e.g., "take the roast out of the oven after 30 minutes"), corresponding to time-based PM (TBPM) (Einstein and McDaniel 1990). PM tasks can be classified as punctual when there is a unique action to execute or as habitual when the action needs to be executed repeatedly (e.g., taking one's medication at specified intervals everyday) (Einstein et al. 1998; Uttl 2008).

In everyday life, the execution of intentions occurs while performing other activities. These concurrent activities are referred to as the ongoing task in laboratory experiments. Two different paradigms are classically used to evaluate PM. Indeed, PM can be assessed either by task-switch procedures or by dual-task procedures (Bisiacchi et al. 2009). In task-switch procedures, participants have to stop focusing on the ongoing activity when they encounter the PM event and switch to perform the prospective action (Burgess et al. 2003; Gao et al. 2014). In contrast, in dual-task procedures, participants have to perform the ongoing task and PM task simultaneously. Thus, they have to remember and execute prospective intention while also performing the ongoing task when the PM event occurs (Kidder et al. 1997; Kliegel et al. 2001).

Many studies have demonstrated an effect of age on PM, sometimes with paradoxical observations. In a laboratory setting, older adults have been shown to perform more poorly in 
TBPM than in EBPM conditions (Einstein and McDaniel 1990; Jáger and Kliegel 2008; Maylor et al. 2002). Recently, more naturalistic assessments relying on virtual reality have confirmed a greater effect of age on TBPM than on EBPM (Lecouvey et al. 2017). The greater sensitivity of TBPM to the effects of age may stem from the involvement of a higher level of self-initiated processes than in EBPM. For TBPM, as no cue appears within the environment to indicate that the target time is approaching, individuals have to maintain considerable executive control to monitor and manage the passage of time (Einstein et al. 2005). Healthy older adults tend to monitor the clock less often than younger participants in the period approaching the intention, suggesting that difficulty with strategic monitoring of time explains poorer performance for this type of intention (Block et al. 1998, for review; Einstein et al. 1995; El Haj et al. 2013) and consequently in TBPM tasks (Vanneste et al. 2016). Overall, this decline in TBPM can also be interpreted in the light of the frontal hypothesis of aging, according to which age-related disruption of frontal areas leads to executive deficits disturbing TBPM (see Alvarez and Emory 2006, for a review).

Neuroimaging studies of TBPM in healthy young adults have highlighted the involvement of the anterior prefrontal cortex (Brodmann area (BA) 10) in intention retrieval (Burgess et al. 2007, 2011, for reviews; Simons et al. 2006). In a recent functional magnetic resonance imaging (fMRI) study, researchers of our laboratory observed specific patterns of activation for EBPM (i.e., middle occipital and lingual gyri) and TBPM (i.e., superior and middle prefrontal cortex, precuneus) in young adults (Gonneaud et al. 2017). By contrast, similar analyses in older participants failed to reveal any such functional specialization according to the nature of the task. This result lends support to the hypothesis of dedifferentiation of brain networks in aging ( $\mathrm{Li}$ and Lindenberger 1999; Reuter-Lorenz 2002). This inability to use efficient strategic monitoring processes and dedicated neural networks according to the requirements of the PM task may contribute to decreased PM performance. Although higher activity has been found in older adults during both EBPM and TBPM in the 
precuneus and supplementary motor area (SMA), it is unlikely that the recruitment of these regions fulfils a compensatory role, as no correlation has been found between their activity and PM performance. In line with these findings, a specific inability to recruit PM-related brain networks has also been reported in older adults, in conditions where high demands are made on PM and working memory (Peira et al. 2016).

Gao (Gao et al. 2014) conducted an fMRI study in young and older adults using an event-based PM task. The analysis of behavioral data showed that the percentage of correct answers was equivalent between the two groups, but older participants responded less quickly than younger ones. Furthermore, older adults exhibited greater brain activity in the supplementary motor area, the precuneus, and the thalamus than young participants, as previously reported by Gonneaud (Gonneaud et al. 2017). The authors also used diffusion tensor imaging (DTI) to assess the integrity of white-matter microstructure. Diffusion tensor imaging analyses mainly rely on the measure of fractional anisotropy, which reflects the overall directionality of water molecules in axons.

Diffusion tensor imaging studies have highlighted a link between changes in some white matter tracts and age-related cognitive decline, particularly in fronto-hippocampal areas involved in executive functioning (flexibility and inhibition) and memory (Kennedy and Raz 2010; Madden et al 2012). More specifically, several studies have observed fractional anisotropy changes along a gradient running from the anterior to the posterior part of the brain, with the anterior tracts being most impaired (Abe et al. 2008; Barrick et al. 2010; Giorgio et al. 2010). The study by Gao (Gao et al. 2014) is the only one to have assessed the impact of age-related changes in white matter on EBPM using tractography. These authors reported a decrease in mean fractional anisotropy and an increase in mean diffusivity (reflecting the total diffusion of water molecules within brain tissue in each voxel) in older adults compared to younger ones. Moreover, these age-related modifications in white matter 
microstructure were more pronounced in short fibers (i.e., maximum length of $35 \mathrm{~mm}$ ) located in frontal regions than in long fibers (i.e., more than $35 \mathrm{~mm}$ long) connecting distant brain areas. Disruption in these short fibers correlated with a decrease in processing speed during the PM task. These results suggest that efficient frontal areas connectivity is crucial for managing high-level processes involved in cognitive control during PM tasks. However, as the conclusions drawn from this study regarding white matter integrity were based solely on fiber length derived from tractography, they remain to be confirmed using more fine-grained measures of white matter integrity in different tracts.

Although clinical neuropsychology has mainly focused on corticocentric theories, the functions of large-scale cortical brain networks are fundamentally dependent upon interactions with subcortical structures such as the basal ganglia and the cerebellum that undergo complex transformations across the life span (Hogan 2004 for review; Kalpouzos et al. 2009; Ramanoël et al. 2018). The cerebellar and basal ganglia contribution to time perception and processing is critical and very well documented (Coull et al. 2011; Ivry and Keele 1989; Meck 2005). Functional imaging studies of PM found activations in the cerebellum and the prefrontal cortex during maintenance and retrieval of timing events (Cona and Rothen 2019; Gonneaud et al. 2017), suggesting that the fronto-cerebellar loop plays a role in TBPM, subserving strategic monitoring for time estimation. According to these findings, the cerebellum encodes the timing event and projects to the frontal cortex and basal ganglia that play a feed-back role towards the cerebellum to update timing expectations (Raghavan et al. 2016).

To our knowledge, no study has so far explored the association between TBPM and gray matter volume using voxel-based morphometry (VBM). Yet, many MRI studies have highlighted an age-related reduction in gray matter volume, especially in frontal and parietal lobes (Greenwood 2007; Gunning-Dixon et al. 2009; Kalpouzos et al. 2009, 2010). Some 
studies have shown a link between this gray matter atrophy and a decline in cognition, notably episodic memory (Kalpouzos et al. 2009; Ramanoël et al. 2018).

PM is generally impaired in aging, but identifying the neural substrates of this impairment requires further investigation. Our main objective was to better characterize the neural substrates of TBPM impairment in older adults, by comparing them to young adults on gray matter volume and white matter integrity. We hypothesized that older adults would exhibit gray matter loss in frontal regions (responsible for executive functions), parietal regions (involved in attentional processes), basal ganglia structures and cerebellar regions (involved in time estimation) than young adults do. Regarding white matter microstructural integrity, we expected to find lower fractional anisotropy values in older adults in tracts connecting frontal (e.g., uncinate fasciculus, corpus callosum), parietal (e.g., superior longitudinal fasciculus), temporal (e.g., cingulum, fornix) and cerebellar white matter tracts, compared to young adults.

The second objective was to determine the potential role of other cognitive functions in age-related PM decline, by performing regression analyses between the altered brain substrates of PM and other cognitive functions. In the light of the cognitive data available in the literature, we hypothesized that TB performance correlates with retrospective episodic memory, binding in working memory, time estimation, and executive functions.

\section{Materials and Methods}

\section{Participants}

We recruited 22 young healthy adults (18-35 years) and 23 healthy older adults (51-76 years). Most participants (20 young adults and 20 older adults) were the same as those included in a previous study focusing on functional MRI data (Gonneaud et al. 2017). All participants were native French speakers, right-handed, had normal or corrected-to-normal vision, and had completed at least 7 years of education. They did not have any antecedents of 
neurological or psychiatric disorders. Depression was assessed with the Beck Depression Inventory (Beck et al. 1961), and state and trait anxiety with the State-Trait Anxiety Inventory (Parts A and B; Spielberger 2010). In addition, the older participants were screened for cognitive deficits using the Mattis Dementia Rating Scale (Mattis 1976). This study was approved by the regional ethics committee (CPP Nord Ouest III, Caen), and written informed consent was obtained from each participant after a detailed presentation of the study. Participants' characteristics are set out in Table 1.

Table 1. Mean (standard deviation) demographic data for young and older adults.

\begin{tabular}{|c|c|c|c|}
\hline & Young adults $(n=22)$ & Older adults $(n=23)$ & $p$ value \\
\hline Male/female sex ratio & $10 / 12$ & $11 / 12$ & $.87^{1}$ \\
\hline Age in years & $25.4( \pm 5.19)$ & $62.5( \pm 6.05)$ & $<0.001$ \\
\hline Age range & $18-35$ & $51-76$ & \\
\hline Education in years & $14.32( \pm 2.55)$ & $14.43( \pm 2.61)$ & $n s$ \\
\hline MMSE score / 30 & na & $28.66( \pm 0.82)$ & na \\
\hline Mattis Dementia Rating & na & $141.13( \pm 2.49)$ & na \\
\hline \multicolumn{4}{|l|}{ Scale / 144} \\
\hline BDI & $0.771( \pm 1.72)$ & $2.104( \pm 1.92)$ & $<0.05$ \\
\hline STAI-A & $25.55( \pm 4.83)$ & $29.19( \pm 6.81)$ & $<0.05$ \\
\hline STAI-B & $33.32( \pm 6.27)$ & $36.30( \pm 7.58)$ & ns \\
\hline \multicolumn{4}{|c|}{ Note. na: not applicable; $n s$ : nonsignificant; BDI: Beck Depression Inventory; STAI: State-Trait } \\
\hline
\end{tabular}

\section{Prospective memory assessment procedure}


The task used in the present study is described in detail elsewhere (Gonneaud et al. 2014; 2017). Only the essential elements are presented here. The general design and conditions are illustrated in Figure 1.

A dual-task procedure was used to assess TBPM. Participants were invited to perform a semantic categorization task (ongoing task). In addition, for some blocks, a TBPM instruction was added. Participants had to perform simultaneously the ongoing activity and TBPM intentions.

- Ongoing task

Participants were asked to categorize color pictures as natural or manmade items. Each picture was displayed within a $280 \times 280$-pixel white square, bordered by a 20-pixel colored line (with 9 different possible colors). A digital countdown was displayed in the upper right-hand corner of the screen, and was used for the TBPM condition (see below). To avoid any difficulty arising from a failure to correctly remember the response keys (counterbalanced between participants), a reminder was displayed at the bottom of the screen, representing the forefinger-category association. First, the instructions were displayed on the screen for $8 \mathrm{~s}$ (Fig. 1). In order to create an interval between the instructions and the beginning of the task, participants were asked to predict their performance on a 5-point scale ranging from 1 (Very badly) to 5 (Very well) (see "Performance prediction" in Fig. 1). The question remained on the screen for $8 \mathrm{~s}$, and was followed by a fixation cross for $1 \mathrm{~s}$, after which 40 pictures were displayed one by one. Each picture remained on the screen for $2 \mathrm{~s}$, followed by a mask for 1 or $2 \mathrm{~s}$. Participants were asked to answer as quickly and accurately as possible whether each item was natural or manmade. The order of presentation was entirely randomized across participants, who had to categorize 12 sets of 40 pictures. At the end of each set, they had to assess their performance on that set using the same 5-point scale as before (see "Performance postdiction" in Fig. 1). After $8 \mathrm{~s}$, a fixation cross appeared and a new set began. 
- $\quad$ TBPM task

Concurrently with the ongoing task, participants performed a TBPM task that consisted in pressing a key with their middle finger every $30 \mathrm{~s}$. To do so, they could look at the countdown, always visible in the upper right-hand corner of the screen. Participants needed to voluntarily direct their gaze to monitor time. The task was performed within the MRI scanner (see Gonneaud et al. 2014; 2017, for the detailed method and brain activity patterns).

a) Ongoing task only (OG)

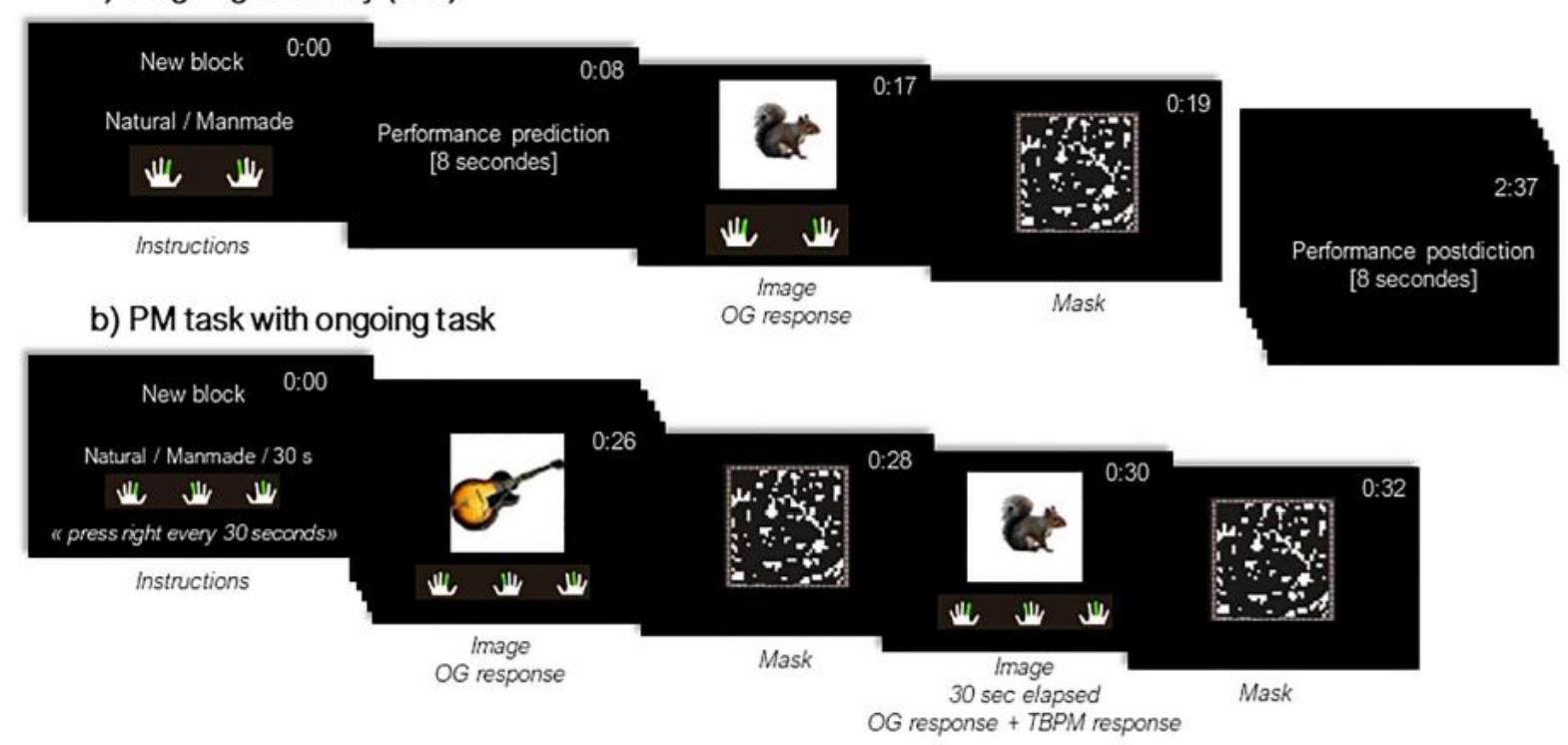

Figure 1. Prospective memory task design. Each block includes instructions, performance prediction, 40 trials (picture + mask), and performance postdiction. The procedure includes the ongoing task only condition (a) and the TBPM condition (b). Adapted from Gonneaud et al. (2014).

\section{Complementary neuropsychological assessment}

To identify the role of other cognitive functions in age-related PM decline, we administered the following supplementary cognitive assessment featuring tests of retrospective episodic memory, memory complaints, executive functions (inhibition, shifting, and updating), binding in working memory, and time estimation. 


\section{Retrospective episodic memory}

Retrospective episodic memory was assessed using the RL-RI16 (Van der Linden et al. 2004). The RL-RI16 comprises three immediate free-recall tests and one cued-recall test of a series of 16 words, followed by a recognition task where these 16 words are intermixed with 32 new ones. After a 20-minute interval, participants perform a delayed recall test. Statistical analyses were performed on the sum on the three immediate free-recall tests (/48).

\section{Memory complaints}

We used the Prospective and Retrospective Memory Questionnaire (PRMQ; Smith et al. 2000) validated in french (Guerdoux-Ninot et al. 2019). This questionnaire provides selfreport measures of memory mistakes in everyday life. It includes 16 questions, eight asking about PM failures (e.g., "Do you decide to do something in a few minutes' time and then forget to do it?"), and eight about retrospective failures (e.g., "Do you fail to recognize a place you have visited before?"). Participants respond on a 5-point Likert scale ranging from 1 (Never) to 5 (Very often). The total of the Prospective and Retrospective Memory Questionnaire score (/80) is calculated from the retrospective failures (/40) and prospective failures (/40) subscores. The higher the score, the more frequent the memory failures.

\section{Executive functions}

- Inhibition was assessed with the Stroop test (Golden 1978). First, participants have to name the color of 100 colored rectangles (naming condition). Second, they have to read 100 names of colors printed in black (reading condition). In the third condition, they have to name the color of the ink in which 100 incongruent color names are printed (interference condition). We measured naming time (assessing processing speed) and an inhibition score was calculated as follows: (interference time - naming) / naming. 
- Shifting was assessed with the Trail Making Test (Reitan 1971). In Part A, participants are required to link digits in ascending order as quickly as possible. In Part B, they are required to shift between alphabet letters and digits in ascending order. Processing speed (in s) is assessed with Part A. The shifting score is calculated as follows: (time needed to perform Part B - Part A) / Part A.

- Updating was assessed with the Running Span test (Pollack et al. 1959), which consists in orally presenting lists of consonants of varying length $(4,6,8,10$ letters). For each list, participants have to repeat in the correct order the $n$ most recent letters $(n$ ranges from 3 to 6 letters). The updating score is the percentage of correct trials calculated from the 16 points.

\section{Binding in working memory}

Binding in working memory was assessed using an original task developed in our laboratory (Quinette et al. 2013) to evaluate the ability to associate and retain verbal and spatial features. Four colored uppercase consonants are displayed in the center of a $5 \times 4$ grid. Four colored crosses are placed randomly in the remaining squares. Participants have to mentally associate the four consonants with the four locations represented by the crosses according to their color, and maintain this association for 1 second. They are then provided with a grid featuring a single lowercase letter printed in black inside a square. Participants have to decide whether this letter-location association matches the one they have previously learned. The score was the number of correct trials out of 20 . We also took into account the reaction times.

\section{Time estimation}

Time estimation was evaluated with a computerized task adapted from (Rueda and Schmitter-Edgecombe 2009), in which participants had to estimate the duration of 10 periods of time (15 s, $30 \mathrm{~s}$, or $40 \mathrm{~s}$ ). For each trial, we calculated the difference in seconds between 
the actual time and the participant's answer. The difference (i.e., deviation) was then divided by the actual time and multiplied by 100 to obtain a percentage of deviation.

\section{MRI acquisition and data processing}

MRI was performed using a Philips Achieva 3T MRI scanner at the Cyceron neuroimaging center (Caen, France). For each participant, a high-resolution T1-weighted anatomical image was also acquired, using a three-dimensional fast-field echo sequence (repetition time $=20 \mathrm{~ms}$, echo time $=4.6 \mathrm{~ms}$, flip angle $=10^{\circ}, 180$ slices, slice thickness $=1$ $\mathrm{mm}$, field of view $=256 \times 256 \mathrm{~mm}^{2}$, matrix $\left.=256 \times 256\right)$.

For the diffusion tensor imaging acquisition, 70 axial slices were acquired with spin echo sequence (32 directions at $b=1000 \mathrm{~s} / \mathrm{mm}^{2}$, repetition time $=10000 \mathrm{~ms}$, echo time $=82$ ms, flip angle $=90^{\circ}$, field of view $=224 \times 224 \mathrm{~mm}^{2}$, acquisition matrix $=112 \times 112$ pixels, acquisition voxel size $=2 \times 2 \mathrm{~mm}^{3}$, and non-diffusion weighted picture at $b=0 \mathrm{~s} / \mathrm{mm}^{2}$ ).

\section{Voxel-based morphometry}

The volumetric MRI data were analyzed using Statistical Parametric Mapping software (SPM12; Wellcome Department of Cognitive Neurology, Institute of Neurology, London, UK). Preprocessing steps included segmentation of the MRI data into gray matter and spatial normalization to the Montreal Neurological Institute $(\mathrm{MNI})$ template $($ voxel size $=$ $1.5 \mathrm{~mm}^{3}$, matrix $\left.=121 \times 145 \times 121\right)$. The normalized gray matter images were modulated by the Jacobian determinants to correct for nonlinear warping only, so that the resulting brain volumes were corrected for brain size. The resulting images were smoothed by a Gaussian kernel of $8 \mathrm{~mm}$ full width at half maximum. Gray matter volume density reflected cerebral macrostructure and numerically corresponded to the mean gray matter per unit volume for each significant cluster. 


\section{Tract-based spatial statistics}

The participants' diffusion-weighted imaging scans were preprocessed to create fractional anisotropy images using the FSL Diffusion Toolbox (http://fsl.fmrib.ox.ac.uk/fsl/ fslwiki/FDT) that is part of the FSL 5.0 toolbox for medical image analysis (Smith et al. 2004). For each participant, the 32 diffusion-weighted imaging scans were first corrected for distortions due to eddy currents and aligned to the $b=0 \mathrm{~s} / \mathrm{mm} 2$ image using rigid-body registration for motion correction (Jenkinson et al. 2002). Fractional anisotropy images were then created by fitting a tensor model to the diffusion images, and were further processed using Tract-Based Spatial Statistics (TBSS). Briefly, all participants' fractional anisotropy data were aligned in MNI space using the nonlinear registration tool (FNIRT), which uses a bspline representation of the registration warp field (Rueckert et al. 1999), resulting in fractional anisotropy maps with a matrix size of $182 \times 218 \times 182$ and a voxel size of $1 \times 1 \times 1$

$\mathrm{mm}^{3}$. Next, the mean fractional anisotropy image was calculated and thinned to create a mean fractional anisotropy skeleton representing the centers of all tracts common to the group. Each participant's aligned fractional anisotropy image was thresholded at 0.3 to exclude low fractional anisotropy values that could be contaminated with partial volume effects from other non- white matter tissues and to minimize between-participants variability. The resulting image was then projected onto the mean skeleton by filling every voxel of the latter with the maximum fractional anisotropy value perpendicular to the skeleton structure. Voxel-based statistics were performed on these skeletonized images.

\section{Statistical analyses}

\section{Comparison of PM scores in older adults and young adults}

We first tested for normality of the distribution of PM scores (i.e., percentage of correct responses) using the Kolmogorov-Smirnov test, and for variance homogeneity using the Levene test. PM scores were then compared between groups using Student $t$ tests. To measure 
the magnitude of the effects, we also computed Cohen's $d$ (Cohen 1988). Cohen defines effect sizes as small when $d$ is approximately 0.2 , medium when $d$ is approximately 0.5 , and large if $d$ exceeds 0.8 . Statistical analyses were performed with STATISTICA 7 software (StatSoft Inc.).

Whole-brain comparison of gray matter and white matter integrity between older adults and young adults

A whole-brain analysis was performed to compare older adults and young adults on gray matter volume. We used an explicit mask with a threshold of 0.5 for gray matter voxel analyses. Differences in gray matter volume are reported for a minimum of 100 voxels, at a statistical threshold of $p<0.05$, and after family-wise error correction for multiple comparisons. Finally, MNI coordinates of voxels were labelled using the Automated Anatomical Labeling atlas (Tzourio-Mazoyer et al. 2002).

Regarding white matter, nonparametric permutation tests (Nichols and Holmes, 2002) were performed between the older adults and young adults groups. For each comparison, 5000 permutations were performed, and the data were Family-wise error-corrected for multiple comparisons $(p<0.05)$ using threshold-free cluster enhancement (Threshold-free Cluster Enhancement; Smith and Nichols 2009) for clusterwise correction. This statistical toolbox was implemented in FSL 5.0 (http://fsl.fmrib. ox.ac.uk/fsl/fslwiki/Randomise). Data were considered significant at $p<0.05$ (Threshold-free Cluster Enhancement) with a minimum cluster size of 20 voxels. Identified structures were labelled using the John Hopkins University International Consortium for Brain Mapping atlas.

\section{Regression analyses}

Before performing regression analyses, we extracted signal values in the significant clusters obtained from Voxel-Based Morphometry and Tract-Based Spatial Statistics. In order to identify the brain correlates of PM decline, both gray matter volume and white matter measures were correlated with TBPM scores in the older group. Then, to demonstrate the 
specificity of the results, we searched for correlations in young subjects. To determine whether other cognitive functions might contribute to PM decline, correlation analyses were performed in the older adult group between scores obtained in the complementary neuropsychological assessment and TB scores only or ongoing task with TB items. Then, we conducted regression analyses between signal values in the clusters that were significantly correlated with TBPM performance and the cognitive scores collected during the complementary neuropsychological assessment.

\section{Results}

\section{Effect of age on TBPM}

The analysis of the ongoing task alone revealed that the two groups had equivalent performance $(t(43)=0.78, p=0.48, d=0.23)$. However, when a PM instruction was added, performance on the ongoing task (number of correct responses for the ongoing task) significantly decreased in older adults compared with young adults $(t(43)=3.57, p<0.001, d$ = 1.07). Finally, analysis of TBPM items only revealed that older adults recalled fewer intentions than young adults $(t(43)=4.06, p<0.001, d=1.21$; see Fig. 2$)$.

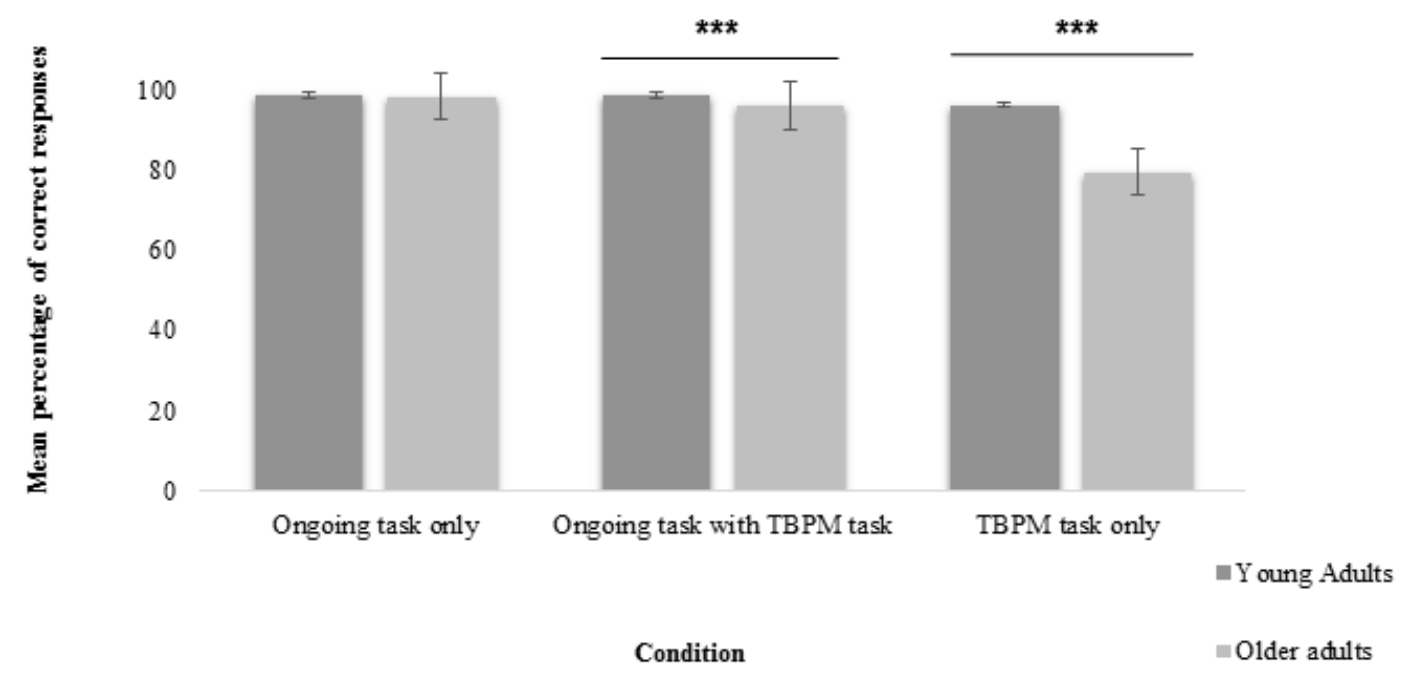


Figure 2. Behavioral results. From left to right: Percentage of correct presses in the ongoing task, the ongoing task with TBPM task, and the TBPM task (i.e., prospective items only) for young and older adults. $* * * p<0.001$.

\section{Relationship between PM decline and other cognitive functions}

Older adults performed more poorly than young adults on few cognitive tests, i.e., retrospective episodic memory, processing speed, inhibition, and binding in working memory while shifting, updating, and time estimation performances were preserved. Results are reported in Table 2 .

Table 2. Young and older adults' mean performances (standard deviation) on the complementary cognitive assessment.

\begin{tabular}{|c|c|c|c|c|}
\hline Cognitive function & Test & Young adults & Older adults & $p$ \\
\hline $\begin{array}{l}\text { Retrospective episodic } \\
\text { memory }\end{array}$ & RL-RI-16 & $38.27( \pm 4.59)$ & $33.04( \pm 5.48)$ & $<0.01$ \\
\hline \multirow[t]{3}{*}{ Memory complaints } & $\begin{array}{l}\text { PRMQ/ } \\
\text { Prospective part }\end{array}$ & $18.23( \pm 2.98)$ & $18.52( \pm 4.21)$ & .79 \\
\hline & PRMQ/ & $14.5( \pm 2.91)$ & $17.22( \pm 3.92)$ & $<0.05$ \\
\hline & Retrospective part & & & \\
\hline \multirow[t]{2}{*}{ Processing speed } & $\begin{array}{l}\text { Stroop (naming } \\
\text { condition) }\end{array}$ & $53.68( \pm 6.37)$ & $58.13( \pm 7.43)$ & $<0.05$ \\
\hline & TMTA & $23.00( \pm 6.43)$ & $34.04( \pm 8.51)$ & $<0.001$ \\
\hline \multicolumn{5}{|l|}{ Executive functions } \\
\hline Shifting & TMT B-A & $118.79( \pm 69.72)$ & $122.22( \pm 76.59)$ & .87 \\
\hline Inhibition & $\begin{array}{l}\text { Stroop (interference } \\
\text { condition) }\end{array}$ & $0.63( \pm 0.18)$ & $1.13( \pm 0.54)$ & $<0.001$ \\
\hline Updating & Running Span & $73.41( \pm 11.75)$ & $73.78( \pm 11.85)$ & .91 \\
\hline Binding in working & Binding task & & & \\
\hline
\end{tabular}


memory

$\begin{array}{lllll} & \text { Correct response } & 18.96( \pm 1.05) & 15.22( \pm 3.04) & <0.001 \\ \text { Reaction times in s } & 1615( \pm 318.80) & 1864.31( \pm 254.48) & <0.01 \\ \text { Time estimation } & \text { Time estimation } & 30.96( \pm 26.80) & 37.76( \pm 15.54) & .30 \\ & \text { task } & & & \end{array}$

Note. PRMQ = Prospective and Retrospective Memory Questionnaire; TMT = Trail Making Test.

No significant correlations were found between the different cognitive scores collected and TB performance. In contrast, Trail Making Test scores, reflecting shifting abilities $(r=-$ $0.47, p=0.026)$ and binding in working memory abilities $(r=0.49, p=0.018)$ correlated with the ongoing task with TB items.

\section{Age-related changes in gray matter volume}

Voxel-wise comparisons of gray matter volume (Fig. 3; see Appendix A for details in Supplementary Materials) revealed that older adults had significantly lower gray matter volume than young adults in the temporal lobe, particularly in the temporal poles and the insula (BA 48), extending to the superior temporal gyrus (Brodmann area 41), parahippocampal gyrus (BA 34), hippocampus, thalamus, and caudate nucleus. We also observed a decrease in gray matter volume in frontal regions (BAs 4, 6, 8, 9, 10, 11, and 12), especially in the anterior, superior and inferior frontal gyri, as well as in posterior cortical areas including the cuneus (BA 17), and lingual (BA 18/19) and fusiform (BA 37) gyri. No significant results were found in the reverse contrast (older > young adults). 


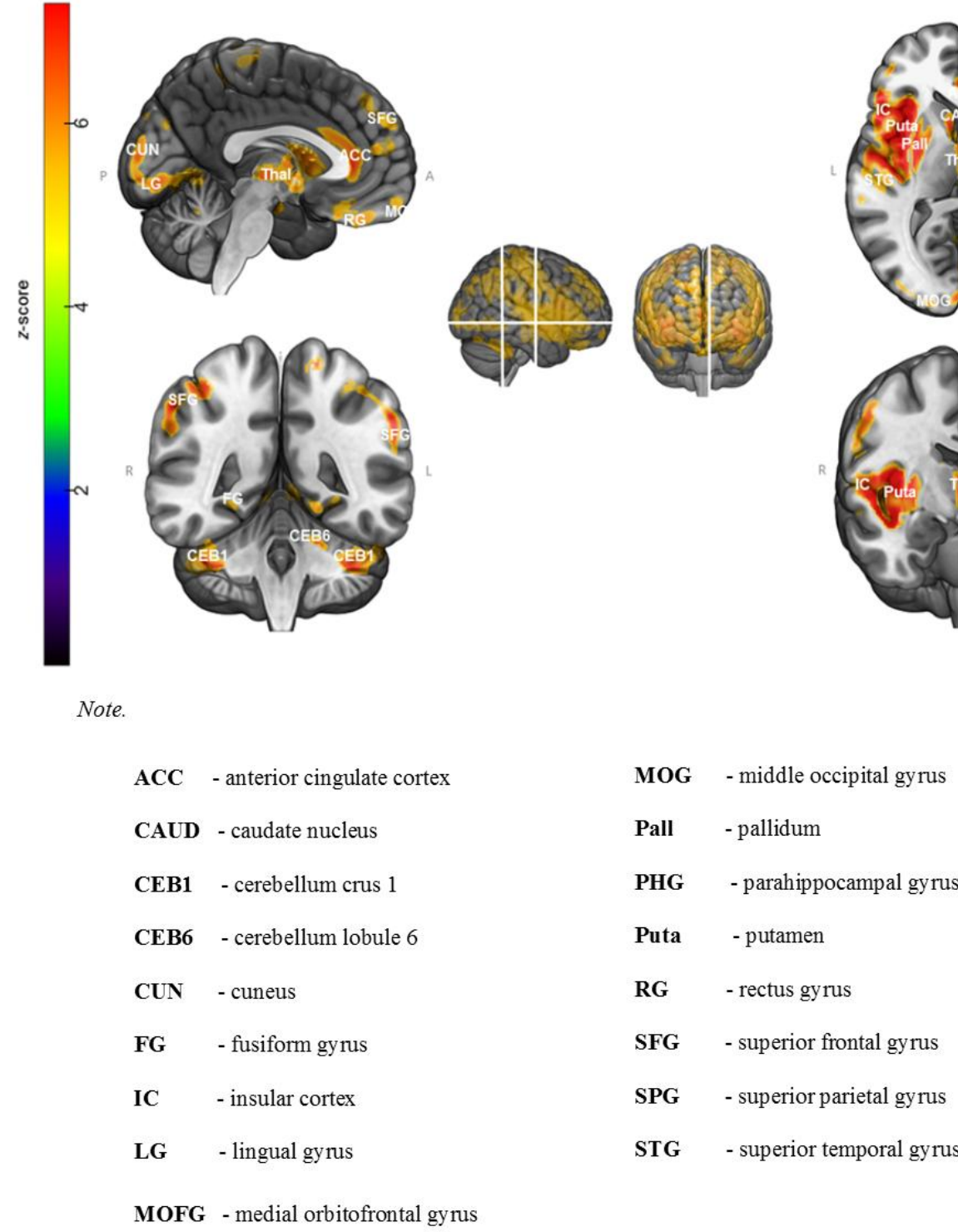

Figure 3. Pattern of gray matter atrophy in older adults compared with young adults.

Results are presented at $p<0.05$ (Family-Wise Error-corrected, cluster size $>100$ voxels). 


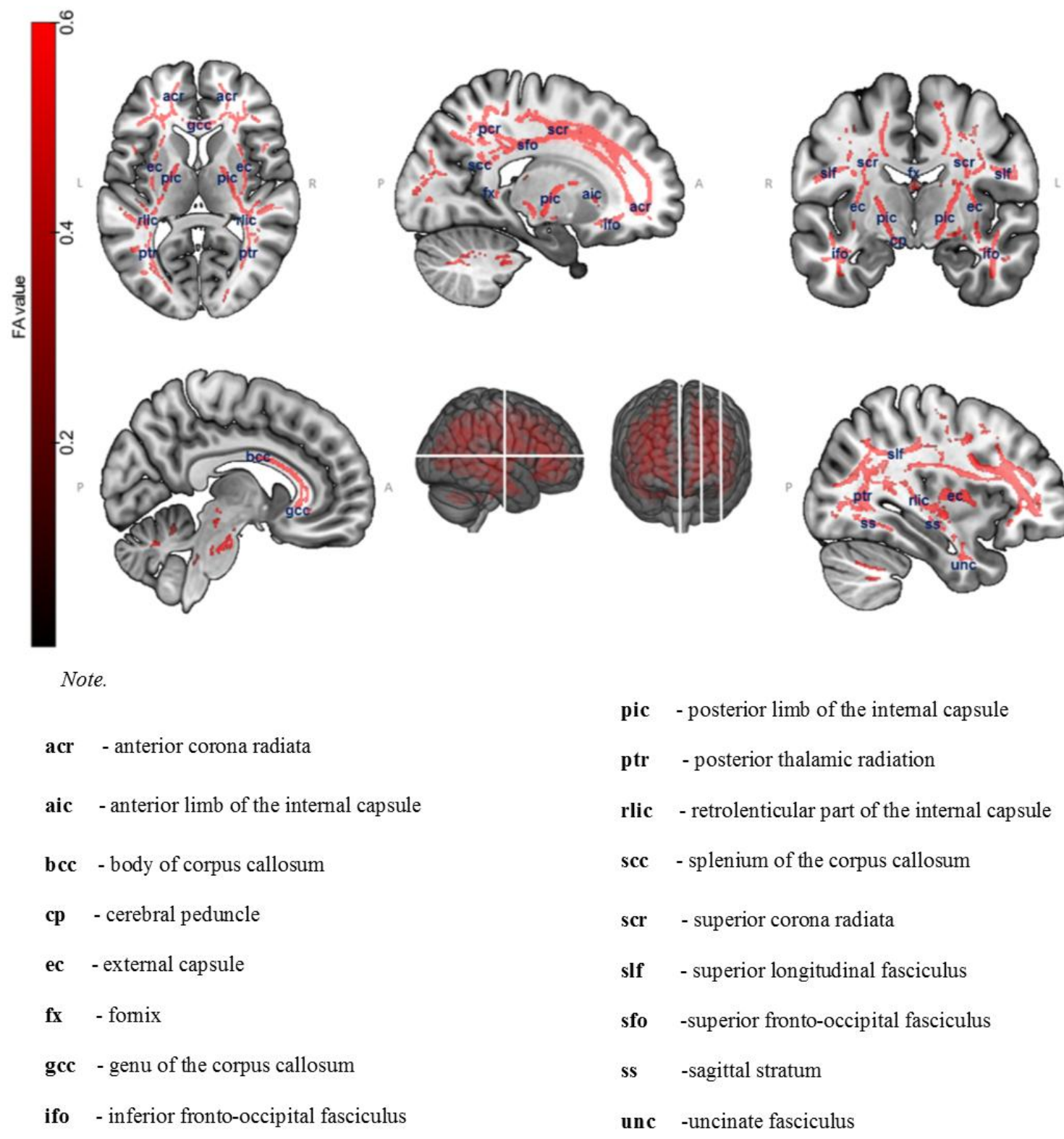

Figure 4. Voxel-wise comparisons of fractional anisotropy values between older and young adults using nonparametric permutation tests (5000 permutations, $p<0.05$, Family-Wise Error -corrected, Threshold-free Cluster Enhancement for cluster-wise correction). $P$-value maps are shown as (1-p) images, displayed on a T1-weighted MRI in MNI space.

Tract-based Spatial Statistics revealed lower fractional anisotropy values for older adults compared with young adults (5000 permutations, $p<0.05$, Family-Wise Errorcorrected, Threshold-free Cluster Enhancement) in the corona radiata, corpus callosum (genu, 
body, and splenium), uncinate fasciculi, superior longitudinal fasciculi, posterior thalamic radiations, posterior and retrolenticular parts of the internal capsule, external capsules, sagittal stratum bilaterally, and inferior, middle, superior peduncles tracts of cerebellar cortex. Overall, white matter alterations were more prominent in the anterior tracts than in the posterior ones (Fig. 4). No significant results were found for the reverse contrast (older > young adults).

\section{Relationships between brain alterations and TBPM performance}

No significant correlations were found between gray matter volume and TBPM performance neither in young adults nor in older adults.

By contrast, for white matter integrity, regression analyses revealed positive correlations between TBPM scores and fractional anisotropy values in white matter tracts, including the right posterior corona radiata $(r=0.47, p<0.02)$, right fornix $(r=0.45, p<$ 0.05), external capsule $(r=0.44, p<0.05)$, left retrolenticular part of the internal capsule $(r=$ $0.41, p<0.05$ ), and right posterior thalamic radiation, although the correlation for the latter only approached the significance threshold $(r=0.37, p=0.08)$. In young adults, no significant correlation was found between TBPM scores and fractional anisotropy values in those white matter tracts, i.e., the right posterior corona radiata $(r=0.19, p=0.37)$, right fornix $(r=0.35$, $p=0.11)$, external capsule $(r=0.31, p=0.16)$, left retrolenticular part of the internal capsule $(r=0.19, p=0.38)$, and right posterior thalamic radiation $(r=0.08, p=0.71)$. Results are displayed in Supplementary Materials (Appendix B).

\section{Relationship between neural substrates of PM and other cognitive functions}

We then examined correlations between fractional anisotropy values (associated to PM) and other cognitive functions in older adults. Scores on the prospective part of the Prospective and Retrospective Memory Questionnaire were negatively correlated to the integrity of the 
left retrolenticular internal capsule $(r=-0.53, p=0.009)$ and right fornix $(r=-0.50, p=$ 0.015). Scores on the retrospective part of the Prospective and Retrospective Memory Questionnaire were negatively correlated with fractional anisotropy values in the right posterior thalamic radiation $(r=-0.44, p=0.035)$ and right fornix $(r=-0.45, p=0.031)$. Performance on the Stroop test (naming time) correlated with fractional anisotropy values in the right external capsule $(r=-0.57, p=0.005)$ and right fornix $(r=-0.47, p=0.024)$. Finally, binding performance (reaction times) was negatively correlated to the integrity of the right posterior thalamic radiation $(r=-0.42, p=0.046)$ and right external capsule $(r=-0.55, p=$ 0.007).

\section{Discussion}

The present study investigated the neural substrates of age-related decline in TBPM using a laboratory task combined with a neuropsychological assessment, structural MRI, and diffusion tensor imaging. This approach allowed us to examine the respective effects of agerelated gray matter atrophy and loss of white matter integrity on TBPM.

While older adults had no difficulty performing the ongoing task alone (semantic categorization of pictures), they performed more poorly than young adults on the ongoing task when the TBPM task was added. As the TBPM task was perceived as challenging by older adults, they focused on that task to the detriment of the ongoing task. They had insufficient resources to effectively perform both tasks. The decline in TBPM performance in older adults may also reflect an inability to disengage their attention from external information (ongoing task) and focus on intention maintenance (TBPM task) (Burgess et al. 2007). This idea is supported by the fact that ongoing scores with TBPM task of older adults was related to shifting performance. We found another association between binding and ongoing scores with TBPM task. Previous studies have found that binding mediates the age effect on PM (Gonneaud et al. 2011; Lecouvey et al. 2017), the latter study using also a TBPM task. As 
previously reported in the literature, older individuals have greater difficulties with time monitoring, impairing their TBPM performance (Einstein et al. 1995). The lack of correlation between time estimation and TBPM scores in our study can be due to the fact that older adults have difficulties only in time perception for long targets durations (Lustig 2003, for review). The durations of the delay in our task were probably too short to be associated with the decline of TBPM.

Overall, the decline in TBPM performance can be attributed to a difficulty to recruit sufficient attention and self-initiated resources to continue monitoring time throughout the task (Jáger and Kliegel 2008; Lecouvey et al. 2017; Maylor et al. 2002; Park et al. 1997).

At the cerebral level, a voxel-based morphometry analysis comparing young and older adults revealed a pattern of gray matter atrophy consistent with previous studies (Ramanoël et al. 2018; Tisserand et al. 2002), and confirming the sensitivity of frontal areas to aging (Gunning-Dixon et al. 2009; Kalpouzos et al. 2009). Although this pattern of brain atrophy encompassed several regions crucial to PM, we surprisingly failed to find any significant correlations between the volume of these brain regions and TBPM performance in older adults. This result suggests that the age-related decline in PM is not directly related to gray matter shrinkage.

The analysis of white matter integrity revealed that older adults had lower fractional anisotropy values in anterior tracts (i.e., uncinate fasciculi, anterior corona radiata, genu and body of corpus callosum, external capsule) and, to a lesser extent, posterior tracts (superior longitudinal fasciculi, posterior thalamic radiations, retrolenticular parts of internal capsule, and sagittal stratum bilaterally). These results are consistent with previous studies showing that the anterior part of the brain is more affected by age than the posterior one (Abe et al. 2002; Barrick et al. 2010; Bennett et al. 2011, 2017; Giorgio et al. 2010; Kantarci et al. 2011; Pfefferbaum et al. 2005; Salat et al. 2005). 
The white matter tracts we found to be altered with age are also known to be involved in cognitive functions that interact with PM. For instance, the anterior part of the corpus callosum plays a role in executive functions (i.e., shifting, inhibition) (Gold et al. 2010; Sullivan et al. 2006). Other tracts such as the fornix and uncinate fasciculus are related to episodic memory (Kennedy and Raz 2010; Metzler-Baddeley et al. 2011).

Contrary to our findings for gray matter, we report, for the first time, significant correlations between age-related decline in TBPM and alterations in white matter microstructure. These correlations concerned the interconnected tracts that form the superior fronto-occipital fasciculus. This network connects the anterior and posterior parts of the brain. This fasciculus, which is part of the inferior fronto-occipital fasciculus (IFOF) (Wu et al. 2016), is known to play a role in the coordination of executive functions (Charlton et al. 2010; Kennedy and Raz 2010) and visual processing (Forkel et al. 2014). More specifically, all projection fibers of the corona radiata are connected to the external and internal capsules, which in turn are connected to the thalamus (Catani et al. 2002; Mamata et al. 2002). These projection tracts are involved in motor functions (Catani and de Schotten 2008) and, more generally, in motor processing speed (Bendlin et al. 2010). The thalamus, connected to the occipital cortex through thalamic radiations, is involved in the preparation and execution of intentions, and is thought to enable anticipatory processing for checking the clock and pressing the response key (Burgess et al. 2001, 2003). Interestingly, the corona radiata is also connected to the supplementary motor area and the precuneus (Vergani et al. 2014), two regions that have previously been found to be activated in an fMRI study of PM with older adults (Gonneaud et al. 2017) and also activated in young adults (Momennejad and Haynes 2012). These findings suggest an involvement in clock-checking related to TBPM intention recall (Oksanen et al. 2014). Connecting the thalamus and the hippocampus, the fornix is involved in episodic memory, which closely interacts with PM (Sutherland and Rodriguez 
1989). The Figure 5 features a synthetic diagram showing how the inferior fronto-occipital fasciculus is linked to gray matter regions involved in PM decline in aging.

The anterior part of the inferior fronto-occipital fasciculus is connected to the rostral prefrontal cortex (rPFC; BA 10), which has been found to be activated during PM tasks (Burgess et al. 2001, 2003, 2011; Okuda et al. 1998, 2007; Simons et al. 2006; Volle et al. 2011), especially for maintaining and retrieving TBPM intentions (Okuda et al. 1998, 2007). Additionally, the rPFC plays a role in time estimation, allowing individuals to estimate when the action must be executed (Momennejad and Haynes 2012). Anticipatory activity occurs in the rPFC before the supplementary motor area activation, reflecting strategic monitoring for clock checks during the TBPM task (Oksanen et al. 2014). Strategic monitoring triggers the motor action for PM recall, suggesting that the rPFC also plays a role in planning (Koechlin et al. 2000; Soon et al. 2008).

While the cerebellum may contribute to TBPM, we found that white matter integrity and the volume of the cerebellum were impaired by aging in accordance with other studies (e.g., Abe et al. 2008) but they were not associated with TBPM decline. This could be due to the fact that the duration of delays was always the same, making it as continuous cyclic whereas the cerebellum is involved in non-cyclic tasks of time perception and longtime perception periods (Breska and Ivry 2016; Coull et al. 2011).

The lack of significant correlations between TBPM and white matter in young adults shows that our findings in older adults are a specific age-related phenomenon. 


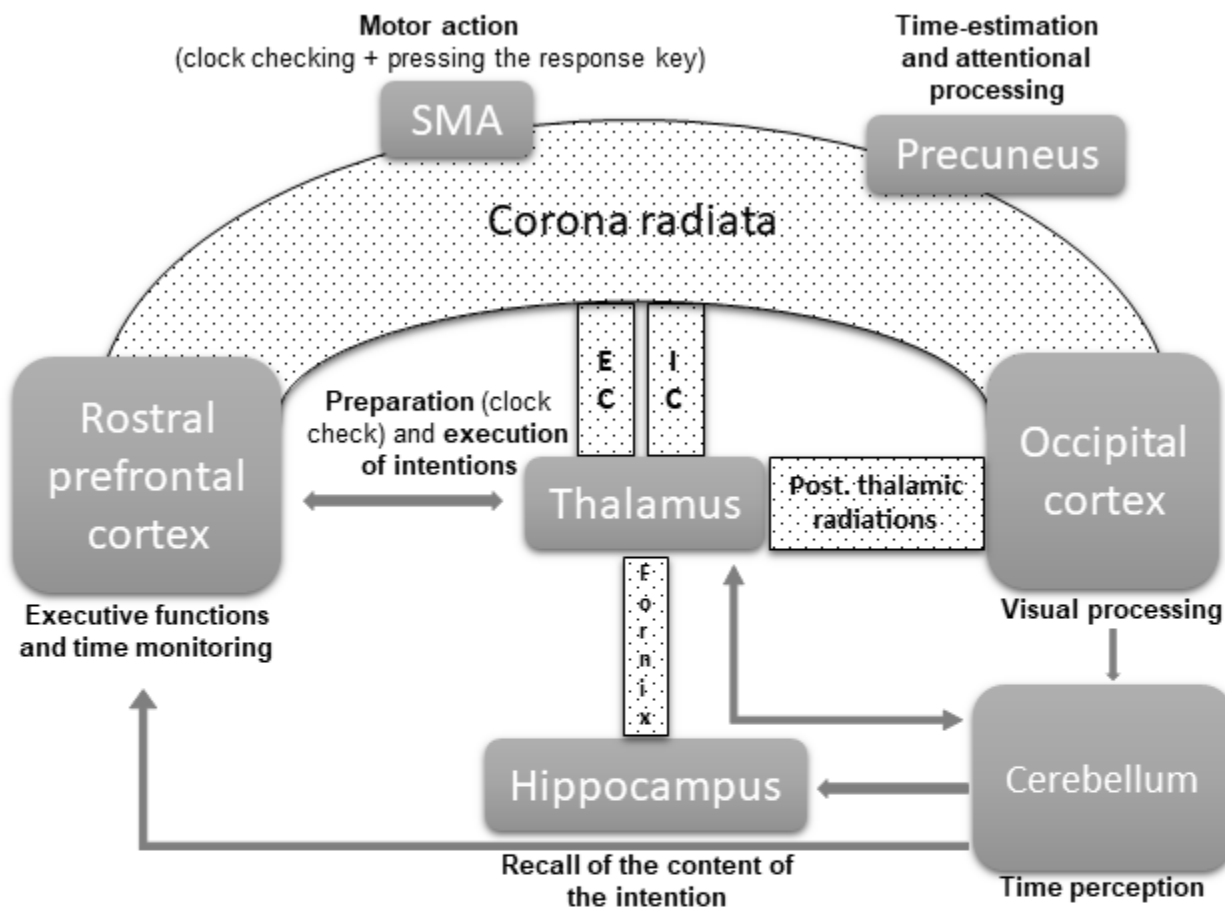

Figure 5. Impaired white-matter tracts associated with the decline in prospective memory in normal aging. The inferior fronto-occipital fasciculus (in small black dots), containing corona radiata, external capsule, internal capsule, fornix and posterior thalamic radiations is associated with gray-matter structures (in gray). The timing network is integrated to the figure, containing the prefrontal cortex, the thalamus, the hippocampus, the supplementary motor area, the parietal cortex (precuneus) and the cerebellum. Gray arrows represent the fronto-cerebellar network loop for processing of time durations.

Regarding correlations between fractional anisotropy values (associated to PM) and other cognitive functions, we found associations with subjective measure of episodic memory, binding and processing speed, suggesting that the decline in PM may, at least in part, be explained by a decline in these functions. This result is not surprising, as other studies have 
shown that PM closely interacts with these functions (Hainselin et al. 2011). More specifically, a decline in retrospective episodic memory contributes to age-related PM decline (Lecouvey et al. 2017). The retrieval of the content of the intention in episodic memory relies on controlled processes that are impaired with age (McDaniel et al. 2000). Our results indicated that the age-related TBPM decline may also stem from difficulties in creating, maintaining, and retrieving associations in memory via the binding process.

We did not find all the expected correlations between TBPM scores and cognitive functions, i.e., executive functions, binding, retrospective episodic memory and time estimation in the group of older adults. This result could be explained by the relative preservation of some abilities (updating and short-intervals time estimation for instance) in the group of older adults. However, some cognitive functions are associated either with fractional anisotropy (i.e. processing speed, subjective episodic memory) or ongoing scores with TBPM task (i.e., shifting), while binding is associated with both, which highlights its key role in age-related PM decline. Finally, processing speed may also contribute to the agerelated decline in PM performance (Kant et al. 2014). The general slowdown observed in aging alters the ability to perform two tasks quickly and concurrently. More specifically, it disturbs the ability to monitor time, and hence to execute intentions at the appropriate moment (Hertzog et al. 2003).

\section{Limitations}

Regarding the PM task, participants were instructed to respond with the right or left index for ongoing activity and right middle finger for PM intentions. Instructions were displayed visually during the task with a picture under the target image, which may have helped to remember the retrospective component of PM intentions "I had to remember to press a key response". However, to be effective, the support of the retrospective component implies the prospective component retrieval. Furthermore, the image of fingers was present 
during the whole task and does not, in itself, make it possible to determine the exact time to interrupt the ongoing task and execute the prospective action. Otherwise, the PM task did not include any measure of clock checking to explore the monitoring of participants. Finally, the PM task was designed not to be too difficult for older participants in order to avoid possible floor effects. Although the PM condition measured correctly PM abilities in older adults, the task was too easy for young participants as attested by a ceiling effect. However, the young adult group was above all used to identify disrupted white matter tracts in the older one in order to explore whether the decline in TBPM performance was associated with white matter disruption in aging.

\section{Conclusion}

Given the literature in the fields of memory and aging, we expected gray matter and white matter alterations in some specific brain areas to be correlated with TBPM performance. However, we only found significant associations for fractional anisotropy values. This suggests that PM, particularly TBPM, is more sensitive to age-related alterations of white matter integrity than to changes in gray matter volume. These results confirm, and extend to the field of PM, the view that a disconnection process, rather than neuronal loss, may be a major mechanism in aging, contributing to cognitive decline (Bennett and Madden 2014; Liu et al. 2017, for a review; O'Sullivan et al. 2001; Sala et al. 2012). Age-related TBPM decline is related to disruptions in the white matter tracts that constitute the inferior fronto-occipital fasciculus. We surmise that PM decline is first associated with the disruption of white matter tracts, then with gray matter atrophy. In this case, it would be interesting to include older participants, to observe the PM decline over time and find correlations between gray matter and PM performance.

\section{Funding}

Association France-Alzheimer and Ministère de 1'Enseignement Supérieur et de la Recherche. 
This study was approved by the Nord-Ouest III French Ethics Committee.

\section{Conflict of interest}

The authors have no conflicts of interest to disclose.

\section{References}

Abe O, Aoki S, Hayashi N, Yamada H, Kunimatsu A, Mori H, Yoshikawa T, Okubo T, Ohtomo K. 2002. Normal aging in the central nervous system: Quantitative MR diffusion-tensor analysis. Neurobiol Aging. 23(3):433-441. doi:10.1016/S0197-4580(01)00318-9.

Abe O, Yamasue H, Aoki S, Suga M, Yamada H, Kasai K, Masutani Y, Kato Nobuyuki, Kato Nobumasa, Ohtomo K. 2008. Aging in the CNS: Comparison of gray/white matter volume and diffusion tensor data. Neurobiol Aging. 29(1):102-116. doi:10.1016/j.neurobiolaging.2006.09.003.

Alvarez JA, Emory E. 2006. Executive function and the frontal lobes: A meta-analytic review. Neuropsychol Rev. 16(1):17-42. doi:10.1007/s11065-006-9002-x.

Barrick TR, Charlton RA, Clark CA, Markus HS. 2010. White matter structural decline in normal ageing: A prospective longitudinal study using tract-based spatial statistics. Neuroimage. 51(2):565-577. doi:10.1016/j.neuroimage.2010.02.033.

Beck, A. T., Ward, C., \& Mendelson M. 1961. Beck depression inventory (BDI). Arch Gen Psychiatry. 4(6):561-571. doi:10.1093/ndt/gfr086.

Bendlin BB, Fitzgerald ME, Ries ML, Xu G, Kastman EK, Thiel BW, Rowley HA, Lazar M, Alexander AL, Johnson SC. 2010. White Matter in Aging and Cognition: A Cross-Sectional Study of Microstructure in Adults Aged Eighteen to Eighty-Three. Dev Neuropsychol. 35(3):257-277. doi:10.1080/87565641003696775. http://www.tandfonline.com/doi/abs/10.1080/87565641003696775.

Bennett IJ, Greenia DE, Maillard P, Sajjadi SA, DeCarli C, Corrada MM, Kawas CH. 2017. Agerelated white matter integrity differences in oldest-old without dementia. Neurobiol Aging. 56:108114. doi:10.1016/j.neurobiolaging.2017.04.013. 
http://dx.doi.org/10.1016/j.neurobiolaging.2017.04.013.

Bennett IJ, Madden DJ. 2014. Disconnected aging: cerebral white matter integrity and age-related differences in cognition. Neuroscience. 276:187-205. doi:10.1016/j.neuroscience.2013.11.026.

Bennett IJ, Madden DJ, Vaidya CJ, Howard JH, Howard D V. 2011. White matter integrity correlates of implicit sequence learning in healthy aging. Neurobiol Aging. 32(12):2317.e1-2317.e12. doi:10.1016/j.neurobiolaging.2010.03.017. https://linkinghub.elsevier.com/retrieve/pii/S0197458010001491.

Bisiacchi PS, Schiff S, Ciccola A, Kliegel M. 2009. The role of dual-task and task-switch in prospective memory: Behavioural data and neural correlates. Neuropsychologia. 47(5):1362-1373. doi:10.1016/j.neuropsychologia.2009.01.034. https://linkinghub.elsevier.com/retrieve/pii/S0028393209000426.

Block RA, Zakay D, Hancock PA. 1998. Human aging and duration judgments: A meta-analytic review. Psychol Aging. 13(4):584-596. doi:10.1037/0882-7974.13.4.584.

Breska A, Ivry RB. 2016. Taxonomies of Timing: Where Does the Cerebellum Fit In ? Curr Opin Behav Sci. 8:282-288. doi:10.1016/j.cobeha.2016.02.034.

Burgess PW, Dumontheil I, Gilbert SJ. 2007. The gateway hypothesis of rostral prefrontal cortex (area 10) function. Trends Cogn Sci. 11(7):290-298. doi:10.1016/j.tics.2007.05.004. https://linkinghub.elsevier.com/retrieve/pii/S1364661307001283.

Burgess PW, Gonen-Yaacovi G, Volle E. 2011. Functional neuroimaging studies of prospective memory: What have we learnt so far? Neuropsychologia. 49(8):2246-2257. doi:10.1016/j.neuropsychologia.2011.02.014. http://dx.doi.org/10.1016/j.neuropsychologia.2011.02.014.

Burgess PW, Quayle A, Frith CD. 2001. Brain regions involved in prospective memory as determined by positron emission tomography. Neuropsychologia. 39(6):545-555. doi:10.1016/S00283932(00)00149-4. http://discovery.ucl.ac.uk/4146/. 
Burgess PW, Scott SK, Frith CD. 2003. The role of the rostral frontal cortex (area 10) in prospective memory: A lateral versus medial dissociation. Neuropsychologia. 41(8):906-918. doi:10.1016/S0028-3932(02)00327-5.

Catani M, Howard RJ, Pajevic S, Jones DK. 2002. Virtual in Vivo interactive dissection of white matter fasciculi in the human brain. Neuroimage. 17(1):77-94. doi:10.1006/nimg.2002.1136.

Catani M, De Schotten MT. 2008. A diffusion tensor imaging tractography atlas for virtual in vivo dissections. Cortex. 44(8):1105-1132. doi:10.1016/j.cortex.2008.05.004.

Charlton RA, Barrick TR, Lawes INC, Markus HS, Morris RG. 2010. White matter pathways associated with working memory in normal aging. Cortex. 46(4):474-489. doi:10.1016/j.cortex.2009.07.005. http://dx.doi.org/10.1016/j.cortex.2009.07.005.

Cohen J. 1988. Statistical power analysis for the behavorial sciences (2nd ed.). Hillsdale, NJ: Lawrence Erlbaum Associates, Publishers.

Cona G, Rothen N. 2019. Neuropsychological and physiological correlates of prospective memory. Current is. Rummel J, McDaniel MA, editors. Abingdon-on-Thames (United Kingdom): Routledge.

Coull JT, Cheng R, Meck WH. 2011. Neuroanatomical and Neurochemical Substrates of Timing. Neuropsychopharmacology. 36:3-25. doi:10.1038/npp.2010.113.

Einstein GO, McDaniel MA. 1990. Normal aging and prospective memory. J Exp Psychol Learn Mem Cogn. 16(4):717-726.

Einstein GO, McDaniel MA, Richardson SL, Guynn MJ, Cunfer A. 1995. Aging and prospective memory: examining the influences of self-initiated retrieval processes. J Exp Psychol Learn Mem Cogn. 21(4):996-1007. doi:10.1037/0278-7393.21.4.996.

Einstein GO, McDaniel MA, Smith RE, Shaw P. 1998. Habitual Prospective Memory and Aging: Remembering Intentions and Forgetting Actions. Psychol Sci. 9(4):284-288. doi:10.1111/14679280.00056. http://journals.sagepub.com/doi/10.1111/1467-9280.00056. 
Einstein GO, McDaniel MA, Thomas R, Mayfield S, Shank H, Morrisette N, Breneiser J. 2005. Multiple Processes in Prospective Memory Retrieval: Factors Determining Monitoring Versus Spontaneous Retrieval. J Exp Psychol Gen. 134(3):327-342. doi:10.1037/0096-3445.134.3.327. http://doi.apa.org/getdoi.cfm?doi=10.1037/0096-3445.134.3.327.

Forkel SJ, De Schotten MT, Kawadler JM, Dell'Acqua F, Danek A, Catani M. 2014. The anatomy of fronto-occipital connections from early blunt dissections to contemporary tractography. Cortex. 56:73-84. doi:10.1016/j.cortex.2012.09.005. http://dx.doi.org/10.1016/j.cortex.2012.09.005.

Gao J, Cheung RTF, Chan YS, Chu LW, Mak HKF, Lee TMC. 2014. The relevance of short-range fibers to cognitive efficiency and brain activation in aging and dementia. PLoS One. 9(4):1-9. doi:10.1371/journal.pone.0090307.

Giorgio A, Santelli L, Tomassini V, Bosnell R, Smith S, De Stefano N, Johansen-Berg H. 2010. Agerelated changes in grey and white matter structure throughout adulthood. Neuroimage. 51(3):943951. doi:10.1016/j.neuroimage.2010.03.004. http://dx.doi.org/10.1016/j.neuroimage.2010.03.004.

Gold BT, Powell DK, Xuan L, Jicha GA, Smith CD. 2010. Age-related slowing of task switching is associated with decreased integrity of frontoparietal white matter. Neurobiol Aging. 31(3):512522. doi:10.1016/j.neurobiolaging.2008.04.005.

Golden CJ.1976. Identification of brain disorders by the Stroop color and word test. Journal of Clinical Psychology. 32(3):654-658. doi: 10.1002/1097-4679(197607)32:3<654::AIDJCLP2270320336>3.0.CO;2-Z.

Gonneaud J, Kalpouzos GG, Bon L, Viader F, Eustache F, Desgranges BA. 2011. Distinct and shared cognitive functions mediate event and time-based prospective memory impairment in normal ageing. Memory. 19(4):360-377. doi:10.1080/09658211.2011.570765.

Gonneaud J, Lecouvey G, Groussard M, Gaubert M, Landeau B, Mézenge F, de la Sayette V, Eustache F, Desgranges B, Rauchs G. 2017. Functional dedifferentiation and reduced task-related deactivations underlie the age-related decline of prospective memory. Brain Imaging Behav. 11(6):1873-1884. doi:10.1007/s11682-016-9661-z. http://dx.doi.org/10.1007/s11682-016-9661-z. 
Gonneaud J, Rauchs G, Groussard M, Landeau B, Mézenge F, de La Sayette V, Eustache F, Desgranges B. 2014. How do we process event-based and time-based intentions in the brain? An fMRI study of prospective memory in healthy individuals. Hum Brain Mapp. 35(7):3066-3082. doi:10.1002/hbm.22385.

Greenwood PM. 2007. Functional plasticity in cognitive aging: Review and hypothesis.

Neuropsychology. 21(6):657-673. doi:10.1037/0894-4105.21.6.657.

http://doi.apa.org/getdoi.cfm?doi=10.1037/0894-4105.21.6.657.

Guerdoux-ninot E, Martin S, Jailliard A, Brouillet D, Guerdoux-ninot E. 2019. Validity of the French Prospective and Retrospective Memory Questionnaire ( PRMQ ) in healthy controls and in patients with no cognitive impairment, mild cognitive impairment and Alzheimer disease. J Clin Exp Neuropsychol. 41(9):888-904. doi:10.1080/13803395.2019.1625870. https://doi.org/10.1080/13803395.2019.1625870.

Gunning-Dixon FM, Brickman AM, Cheng JC, Alexopoulos GS. 2009. Aging of cerebral white matter: a review of MRI findings. Int J Geriatr Psychiatry. 24(2):109-17. doi:10.1002/gps.2087.

Hainselin M, Quinette P, Desgranges B, Martinaud O, Hannequin D, Sayette V De, Viader F, Eustache F, Hainselin M, Quinette P, et al. 2011. Can We Remember Future Actions yet Forget the Last Two Minutes? Study in Transient Global Amnesia. J Cogn Neurosci. 23(12):4138-4149.

El Haj M, Moroni C, Samson S, Fasotti L, Allain P. 2013. Brain and Cognition Prospective and retrospective time perception are related to mental time travel : Evidence from Alzheimer' $\mathrm{s}$ disease. Brain Cogn. 83:45-51.

Hertzog C, Dixon RA, Hultsch DF, Macdonald SWS. 2003. Latent Change Models of Adult Cognition: Are Changes in Processing Speed and Working Memory Associated With Changes in Episodic Memory ? Psychol Aging. 18(4):755-769. doi:10.1037/0882-7974.18.4.755.

Hogan MJ. 2004. The cerebellum in thought and action : a fronto-cerebellar aging hypothesis. New Ideas Psychol. 22:97-125. doi:10.1016/j.newideapsych.2004.09.002. 
Ivry RB, Keele SW. 1989. Timing functions of the cerebellum. J Cogn Neurosci. 1(2):136-152. doi:10.1162/jocn.1989.1.2.136.

Jáger T, Kliegel M. 2008. Time-Based and Event-Based Prospective Memory Across Adulthood: Underlying Mechanisms and Differential Costs on the Ongoing Task. J Gen Psychol. 135(1):4-22. doi:10.3200/GENP.135.1.4-22. http://www.tandfonline.com/doi/abs/10.3200/GENP.135.1.4-22.

Jenkinson M, Bannister P, Brady M, Smith S. 2002. Improved optimization for the robust and accurate linear registration and motion correction of brain images. Neuroimage. 17(2):825-41. doi:10.1006/nimg.2002.1132. http://www.ncbi.nlm.nih.gov/pubmed/12377157.

Kalpouzos G, Chételat G, Baron JC, Landeau B, Mevel K, Godeau C, Barré L, Constans JM, Viader F, Eustache F, et al. 2009. Voxel-based mapping of brain gray matter volume and glucose metabolism profiles in normal aging. Neurobiol Aging. 30(1):112-124. doi:10.1016/j.neurobiolaging.2007.05.019.

Kalpouzos G, Eriksson J, Sjölie D, Molin J, Nyberg L. 2010. Neurocognitive systems related to realworld prospective memory. PLoS One. 5(10). doi:10.1371/journal.pone.0013304.

Kant N, Berg E Van Den, Zandvoort MJE Van, Frijns CJM, Kappelle LJ, Postma A. 2014. Neuropsychologia Functional correlates of prospective memory in stroke. Neuropsychologia. 60:77-83. doi:10.1016/j.neuropsychologia.2014.05.015.

Kantarci K, Senjem ML, Avula R, Zhang B, Samikoglu AR, Weigand SD, Przybelski SA, Edmonson HA, Vemuri P, Knopman DS, et al. 2011. Diffusion tensor imaging and cognitive function in older adults with no dementia. Neurology. 77(1):26-34. doi:10.1212/WNL.0b013e31822313dc.

Kennedy KM, Raz N. 2010. Aging white natter and cognition: Differential effects of regional variations in diffusion properties on eemory, executive functions, and speed. Neuropsychologia. 47(3):916-927. doi:10.1016/j.neuropsychologia.2009.01.001.Aging.

Kidder DP, Park DC, Hertzog C, Morrell RW. 1997. Prospective memory and aging: The effects of working memory and prospective memory task load. Aging, Neuropsychol Cogn. 4(2):93-112. 
doi:10.1080/13825589708256639.

http://www.tandfonline.com/doi/abs/10.1080/13825589708256639.

Kliegel M, Martin M, McDaniel MA, Einstein GO. 2001. Varying the importance of a prospective memory task: Differential effects across time- and event-based prospective memory. Memory. 9(1):1-11. doi:10.1080/09658210042000003.

Koechlin E, Corrado G, Pietrini P, Grafman J. 2000. Dissociating the role of the medial and lateral anterior prefrontal cortex in human planning. Proc Natl Acad Sci. 97(13):7651-7656. doi:10.1073/pnas.130177397.

Lecouvey G, Gonneaud J, Piolino P, Madeleine S, Orriols E, Fleury P, Eustache F, Desgranges B. 2017. Is binding decline the main source of the ageing effect on prospective memory? A ride in a virtual town. Socioaffective Neurosci Psychol. 7(1):1304610. doi:10.1080/20009011.2017.1304610. https://www.tandfonline.com/doi/full/10.1080/20009011.2017.1304610.

Li S-C, Lindenberger U. 1999. Cross-level unification: A computational exploration of the link between deterioration of neurotransmitter systems and dedifferentiation of cognitive abilities in old age. In: Nilsson L, Markowistch H, editors. Cognitive Neuroscience of Memory. Seatle, Washington: Hogrefe \& Huber. p. 103-146.

Liu H, Yang Y, Xia Y, Zhu W, Leak RK, Wei Z, Wang J, Hu X. 2017. Aging of cerebral white matter. Ageing Res Rev. 34:64-76. doi:10.1016/j.arr.2016.11.006.

Lustig C. 2003. Grandfather's clock: Attention and interval timing in older adults. In W. H. Meck (Ed.), Functional and neural mechanisms of interval timing. In: Warren HM, editor. Functional and neural mechanisms of interval timing. Boca Raton, FL: CRC Press. p. 261-294.

Madden DJ, Bennett IJ, Burzynska A, Potter GG, Chen N, Song AW. 2012. Diffusion tensor imaging of cerebral white matter integrity in cognitive aging. Biochim Biophys Acta - Mol Basis Dis. 1822(3):386-400. doi:10.1016/j.bbadis.2011.08.003. http://linkinghub.elsevier.com/retrieve/pii/S0925443911001736. 
Mamata H, Mamata Y, Westin C, Shenton ME, Kikinis R, Jolesz FA, Maier SE. 2002. Highresolution line scan diffusion tensor MR imaging of white matter fiber tract anatomy. Am J Neuroradiol. 23(1):67-75. http://www.ncbi.nlm.nih.gov/pubmed/11827877.

Mattis S. 1976. Mental status examination for organic mental syndrome in the elderly patients. Bellack L, Karasu T, editors. New-York,NY: Grune and Stratton.

Maylor EA, Smith G, Della Sala S, Logie RH. 2002. Prospective and retrospective memory in normal aging and dementia: An experimental study. Mem Cognit. 30(6):871-884. doi:10.3758/Bf03195773.

McDaniel MA, Einstein GO. 2000. Strategic and automatic processes in prospective memory retrieval: a multiprocess framework. Appl Cogn Psychol. 14(7):S127-S144. doi:10.1002/acp.775. http://doi.wiley.com/10.1002/acp.775.

Meck WH. 2005. Neuropsychology of timing and time perception. Brain Cogn. 58:1-8. doi:10.1016/j.bandc.2004.09.004.

Metzler-Baddeley C, Jones DK, Belaroussi B, Aggleton JP, O’Sullivan MJ. 2011. Frontotemporal Connections in Episodic Memory and Aging: A Diffusion MRI Tractography Study. J Neurosci. 31(37):13236-13245. doi:10.1523/JNEUROSCI.2317-11.2011. http://www.jneurosci.org/cgi/doi/10.1523/JNEUROSCI.2317-11.2011.

Momennejad I, Haynes JD. 2012. Human anterior prefrontal cortex encodes the "what" and "when" of future intentions. Neuroimage. 61(1):139-148. doi:10.1016/j.neuroimage.2012.02.079. http://dx.doi.org/10.1016/j.neuroimage.2012.02.079.

Nichols TE, Holmes AP. 2002. Nonparametric permutation tests for functional neuroimaging: A primer with examples. Hum Brain Mapp. 25(August 1999):1-25. doi:10.1002/hbm.1058 [pii]. http://onlinelibrary.wiley.com/doi/10.1002/hbm.1058/full\%5Cnpapers2://publication/uuid/7A658F FA-74E4-4929-9682-943CE149A77E.

O’Sullivan M, Jones DK, Summers PE, Morris RG, Williams SC, Markus HS. 2001. Evidence for 
cortical "disconnection" as a mechanism of age-related cognitive decline. Neurology. 57(4):632638. doi:10.1212/WNL.57.4.632.

Oksanen KM, Waldum ER, Mcdaniel MA, Braver TS. 2014. Neural Mechanisms of Time-Based Prospective Memory : Evidence for Transient Monitoring. PLoS One. 9(3). doi:https://doi.org/10.1371/journal.pone.0092123.

Okuda J, Fujii T, Ohtake H, Tsukiura T, Yamadori A, Frith CD, Burgess PW. 2007. Differential involvement of regions of rostral prefrontal cortex (Brodmann area 10) in time- and event-based prospective memory. Int J Psychophysiol. 64(3):233-246. doi:10.1016/j.ijpsycho.2006.09.009.

Okuda J, Fujii T, Yamadori A, Kawashima R, Tsukiura T, Fukatsu R, Suzuki K, Ito M, Fukuda H. 1998. Participation of the prefrontal cortices in prospective memory: Evidence from a PET tudy in humans. Neurosci Lett. 253(2):127-130. doi:10.1016/S0304-3940(98)00628-4.

Park DC, Hertzog C, Kidder DP, Morrell RW, et al. 1997. Effect of age on event-based and timebased prospective memory. Psychol Aging. 12(2):314-327. doi:10.1037//0882-7974.12.2.314. http://doi.apa.org/getdoi.cfm?doi=10.1037/0882-7974.12.2.314.

Peira N, Ziaei M, Persson J. 2016. Age differences in brain systems supporting transient and sustained processes involved in prospective memory and working memory. Neuroimage. 125:745-755. doi:10.1016/j.neuroimage.2015.10.075. http://dx.doi.org/10.1016/j.neuroimage.2015.10.075.

Pfefferbaum A, Adalsteinsson E, Sullivan E V. 2005. Frontal circuitry degradation marks healthy adult aging: Evidence from diffusion tensor imaging. Neuroimage. 26(3):891-899. doi:10.1016/j.neuroimage.2005.02.034.

Pollack I, Johnson LB, Knaff PR.1959. Running memory span. Journal of experimental Psychology. 57(3): 137. doi: 10.1037/h0046137

Quinette P, Guillery-Girard B, Hainselin M, Laisney M, Desgranges B, Eustache F. 2013. Évaluation Du Buffer Épisodique : Deux Épreuves Testant Les Capacités D’Association Et De Stockage D’Informations Verbales Et Spatiales. Rev Neuropsychol. 5(1):56-62. doi:doi:10.1684/nrp.2013.0254. 
Raghavan RT, Prevosto V, Sommer MA. 2016. ScienceDirect Contribution of cerebellar loops to action timing. Curr Opin Behav Sci. 8:28-34. doi:10.1016/j.cobeha.2016.01.008.

Ramanoël S, Hoyau E, Kauffmann L, Renard F, Pichat C, Boudiaf N, Krainik A, Jaillard A, Baciu M. 2018. Gray matter volume and cognitive performance during normal aging. A voxel-based morphometry study. Front Aging Neurosci. 10(AUG):1-10. doi:10.3389/fnagi.2018.00235.

Reitan R. 1971. Trail making test results for normal and brain-damaged children. Percept Mot Skills. 33(2):575-581. doi:10.2466/pms.1971.33.2.575.

Reuter-lorenz PA. 2002. New visions of the aging mind and brain. Trends Cogn Sci. 6(9):394-400.

Rueckert D, Sonoda LI, Hayes C, Hill DLG, Leach MO, Hawkes DJ. 1999. Nonrigid registration using free-form deformations: application to breast MR images. IEEE Trans Med Imaging. 18(8):712-721. doi:10.1109/42.796284. http://ieeexplore.iee.org/document/796284/.

Rueda AD, Schmitter-edgecombe M. 2009. Time Estimation Abilities in Mild Cognitive Impairment and Alzheimer's Disease. Neuropsychology. 23(2):178-188. doi:10.1037/a0014289.

Sala S, Agosta F, Pagani E, Copetti M, Comi G, Filippi M. 2012. Microstructural changes and atrophy in brain white matter tracts with aging. Neurobiol Aging. 33(3):488-498. doi:10.1016/j.neurobiolaging.2010.04.027.

Salat DH, Tuch DS, Greve DN, Van Der Kouwe AJW, Hevelone ND, Zaleta AK, Rosen BR, Fischl B, Corkin S, Diana Rosas H, et al. 2005. Age-related alterations in white matter microstructure measured by diffusion tensor imaging. Neurobiol Aging. 26(8):1215-1227. doi:10.1016/j.neurobiolaging.2004.09.017.

Simons JS, Schölvinck ML, Gilbert SJ, Frith CD, Burgess PW. 2006. Differential components of prospective memory?. Evidence from fMRI. Neuropsychologia. 44(8):1388-1397. doi:10.1016/j.neuropsychologia.2006.01.005.

Smith G, Del Sala S, Logie RH, Maylor EA. 2000. Prospective and retrospective memory in normal ageing and dementia: A questionnaire study. Memory. 8(5):311-321. 
doi:10.1080/09658210050117735.

https://www.tandfonline.com/doi/full/10.1080/09658210050117735.

Smith SM, Jenkinson M, Woolrich MW, Beckmann CF, Behrens TEJ, Johansen-Berg H, Bannister PR, De Luca M, Drobnjak I, Flitney DE, et al. 2004. Advances in functional and structural MR image analysis and implementation as FSL. Neuroimage. 23 Suppl 1:S208-19. doi:10.1016/j.neuroimage.2004.07.051. http://www.ncbi.nlm.nih.gov/pubmed/15501092.

Smith SM, Nichols TE. 2009. Threshold-free cluster enhancement: addressing problems of smoothing, threshold dependence and localisation in cluster inference. Neuroimage. 44(1):83-98. doi:10.1016/j.neuroimage.2008.03.061. http://www.ncbi.nlm.nih.gov/pubmed/18501637.

Soon CS, Brass M, Heinze HJ, Haynes JD. 2008. Unconscious determinants of free decisions in the human brain. Nat Neurosci. 11(5):543-545. doi:10.1038/nn.2112.

Spielberger C. 1983. Manual for the State- Trait anxiety inventory: STAI. Palo alto, CA; Consult Psychol Press.

Sullivan E V., Adalsteinsson E, Pfefferbaum A. 2006. Selective age-related degradation of anterior callosal fiber bundles quantified In vivo with fiber tracking. Cereb Cortex. 16(7):1030-1039. doi:10.1093/cercor/bhj045.

Sutherland RJ, Rodriguez AJ. 1989. The role of the fornix/fimbria and some related subcortical structures in place learning and memory. Behav Brain Res. 32(3):265-277. doi:10.1016/S01664328(89)80059-2.

Tisserand DJ, Pruessner JC, Sanz Arigita EJ, Van Boxtel MPJ, Evans AC, Jolles J, Uylings HBM. 2002. Regional frontal cortical volumes decrease differentially in aging: An MRI study to compare volumetric approaches and voxel-based morphometry. Neuroimage. 17(2):657-669. doi:10.1016/S1053-8119(02)91173-0.

Tzourio-Mazoyer N, Landeau B, Papathanassiou D, Crivello F, Etard O, Delcroix N, Mazoyer B, Joliot M. 2002. Automated anatomical labeling of activations in SPM using a macroscopic 
anatomical parcellation of the MNI MRI single-subject brain. Neuroimage. 15(1):273-89. doi:10.1006/nimg.2001.0978. http://www.ncbi.nlm.nih.gov/pubmed/11771995.

Uttl B. 2008. Transparent meta-analysis of prospective memory and aging. PLoS One. 3(2). doi:10.1371/journal.pone.0001568.

Vanneste S, Baudouin A, Bouazzaoui B, Taconnat L. 2016. Age-related differences in time-based prospective memory: The role of time estimation in the clock monitoring. Memory. 24(6):812825. doi:10.1080/09658211.2015.1054837.

Van der Linden M, Coyette F, Poitrenaud J, Kalafat M, Calacis F, Wyns C, Adam S. 2004. L'épreuve de rappel libre/rappel indicé à 16 items (RL/RI-16). In Van der Liden M, GREMEM, editors, L'évaluation des troubles de la mémoire : Présentation de quatre tests de mémoire épisodique avec leur étalonnage. Marseille : Solal, pp. 25-47.

Vergani F, Lacerda L, Martino J, Attems J, Morris C, Mitchell P, Schotten MT De, Acqua FD. 2014. White matter connections of the supplementary motor area in humans. doi:10.1136/jnnp-2013307492.

Volle E, Gonen-Yaacovi G, de Lacy Costello A, Gilbert SJ, Burgess PW. 2011. The role of rostral prefrontal cortex in prospective memory: A voxel-based lesion study. Neuropsychologia. 49(8):2185-2198. doi:10.1016/j.neuropsychologia.2011.02.045. http://dx.doi.org/10.1016/j.neuropsychologia.2011.02.045.

Wu Y, Sun D, Wang Yong, Wang Yibao. 2016. Subcomponents and Connectivity of the Inferior Fronto-Occipital Fasciculus Revealed by Diffusion Spectrum Imaging Fiber Tracking. Front Neuroanat. 10(September):1-13. doi:10.3389/fnana.2016.00088. 